\title{
CUIDADO DE ENFERMAGEM À CRIANÇA VÍTIMA DE VIOLÊNCIA SEXUAL ATENDIDA EM UNIDADE DE EMERGÊNCIA HOSPITALAR
}

\author{
Nursing care for sexually abused children in hospital emergency \\ units

\section{Cuidado de la enfermería al niño víctima de violencia sexual atendido en unidad de emergencia hospitalaria}

Ruth Oliveira Santos Woiski ${ }^{1}$

Daniele Laís Brandalize Rocha

\begin{abstract}
RESUMO
Objetivos: conhecer como a equipe de enfermagem percebe o cuidado efetivado à criança que sofreu violência sexual ao ser atendida em unidade de emergência hospitalar e especificar, a partir das expressões da equipe de enfermagem, as características que compõem o cuidado de enfermagem em unidade de emergência hospitalar à criança que sofreu violência sexual. Métodos: pesquisa qualitativa, pelo método exploratório-descritivo, utilizando a entrevista semiestruturada com 11 profissionais da equipe de enfermagem de uma unidade de emergência hospitalar. Resultados: pela análise de conteúdo de Bardin (1991), foram compreendidas três Unidades de Contexto e seis Unidades de Significação que revelam a percepção da equipe de enfermagem ao cuidar da criança vítima de violência sexual em unidade de emergência hospitalar. Conclusões: a equipe percebe que o cuidado vai além da técnica, envolvendo o emocional da criança, equipe e família. Percebeu-se o cuidado humanizado, porém sem a sistematização da assistência por meio do processo de enfermagem.
\end{abstract}

Palavras-chave: Percepção. Cuidado da Criança. Violência Sexual.

\begin{abstract}
Objectives: find out how the nursing team perceives care provided to sexually abused children in hospital emergency units based on what is expressed by the nursing team and what are the features that constitute nursing care in hospital emergency units for sexually abused children. Methods: qualitative survey using the exploratory-descriptive method through a semistructured interview with 11 members of the nursing team in a hospital emergency unit. Results: in accordance with Bardin's (1991) content analysis, three Context units and six Meaning units were used to reveal the nursing team's perception while caring for sexually abused children in the hospital emergency unit. Conclusions: the team perceives care as going beyond technique, emotionally involving child, team, and family. It was perceived that human care is provided, but that it is not systematized throughout the nursing care process.
\end{abstract}

Keywords: Perception. Child care. Sexual violence

\section{Resumen}

Objetivos: Conocer cómo el equipo de enfermería percibe el cuidado destinado al niño victima de violencia sexual al ser atendido en una unidad de emergencia hospitalaria y especificar, a partir de las expresiones del equipo de enfermería, las características que conforman el cuidado de enfermería en una unidad de emergencia hospitalaria destinadas al niño que sufrió violencia sexual. Métodos: investigación cualitativa, a través del método exploratorio descriptivo: aplicó la entrevista semiestructurada con 11 profesionales del equipo de enfermería de una unidad de emergencia hospitalaria. Resultados: a través del análisis de contenido de Bardin (1991) se contemplaron tres Unidades de Contexto y seis Unidades de Significación que revelan la percepción del equipo de enfermería al cuidar del niño víctima de violencia sexual en una unidad de emergencia hospitalaria. Conclusiones: el equipo percibió que el cuidado va más allá de la técnica, involucrando el aspecto emocional del niño, el equipo y la familia. Se observó el cuidado humanizado que, no obstante, no contaba con la sistematización de la atención a través del proceso de enfermería.

Palavras clave: Percepción. Cuidado del niño. Violencia sexual.

'Enfermeira, formada pela Faculdades Pequeno Príncipe. Brasil. E-mail: ruthwoiski@yahoo.com.br, ${ }^{2}$ Enfermeira. Mestre em Enfermagem pelo Programa de Pós-Graduação em Enfermagem da UFPR, docente do Curso de Enfermagem Faculdades Pequeno Príncipe, Curitiba/PR. Brasil. E-mail: enferdani2004@yahoo.com.br 
Cuidado à criança vítima de violência sexual Woiski ROS, Rocha DLB

\section{INTRODUCC̃̃O}

A violência sexual infantil, dentre os vários níveis em que pode estar inserida, acontece, principalmente, no próprio âmbito doméstico e é praticada por sujeito em condições superiores de idade, posição social ou econômica e inteligência, usando autoridade sobre a criança indefesa. Este comete um dano físico ou psicológico, contrariamente à vontade da criança ou por consentimento obtido a partir de indução ou sedução enganosa.

Sabe-se que vários casos de violência sexual infantil não são denunciados e muitas crianças sofrem caladas diante deste acontecimento tão nocivo e crescem em um ambiente que as reprime e não contribui para o seu pleno crescimento e desenvolvimento. Porém, os casos que são levados ao atendimento na rede pública de saúde ou a serviços hospitalares de emergência são atendidos por uma equipe multiprofissional e esta deve estar preparada, tanto tecnicamente como emocionalmente, para cuidar desta criança e da família/ responsável que a acompanha.

Obter informações e cuidar de uma criança doente requer do profissional, além do cuidado técnico, imprescindível, o cuidado subjetivo, que envolve a singularidade e a individualidade de cada criança e a forma como esta expressa seus sentimentos e emoções. Mais ainda, coletar a história e cuidar de uma criança vítima de violência sexual envolve, além do cuidado com o físico, tão doloroso, as necessidades de cuidado com o seu sofrimento emocional, que se relaciona com o contexto em que essa violência aconteceu e com todos os símbolos e significações que este acontecimento tem para ela.

Para isto, os profissionais devem estabelecer primeiro um clima de afinidade, harmonia e confiança com a criança, evitando qualquer insinuação de julgamento, sejam no tom de voz ou na expressão facial. ${ }^{2}$ Porém, é importante também que os profissionais avaliem, antes de tudo, a sua própria postura e disponibilidade emocional para atender e discutir assuntos relacionados à violência sexual infantil.

Dentre os profissionais envolvidos neste contexto estão 0 enfermeiro e a equipe de enfermagem. Diante da especificidade do cuidado de enfermagem neste contexto, e entendendo a necessidade de compreender a experiência do processo de cuidar da criança diante da violência sexual, propomos este artigo, como extrato da monografia de conclusão do curso de enfermagem, que teve como objetivos: conhecer como a equipe de enfermagem percebe o cuidado efetivado à criança que sofreu violência sexual ao ser atendida em unidade de emergência hospitalar e especificar, a partir das expressões da equipe de enfermagem, as características que compõem 0 cuidado de enfermagem em unidade de emergência hospitalar à criança que sofreu violência sexual.

A realização de pesquisas na área de enfermagem que envolva o cuidado à criança vítima de violência sexual é de grande relevância, pois possibilita, além de compreender a
Esc Anna Nery Rev Enferm 2010 jan-mar; 14 (1): 143-50

experiência do processo de cuidar da criança diante de um fenômeno tão impactante como este, refletir sobre o cuidado que é realizado de forma a buscar seu aprimoramento.

\section{A criança vítima de violência sexual}

A infância é um período da vida em que o ser humano está em constante aprendizagem a partir do seu mundo concreto e do abstrato, que envolvem a imaginação, sendo a criança capaz de materializar e, ao mesmo tempo, fantasiar sobre o que vivencia. Desse modo, as suas formas de expressão, as ações, comportamentos e diálogos nem sempre são bem compreendidos pelo adulto. As crianças, por sua própria natureza, mostram, por meio de suas ações, o que pensam e 0 que sentem, e o papel dos pais é orientar e proteger, permitindo sempre a expressão de sentimentos. Nessa trajetória, as condições do meio circulante são fundamentais, e o afeto e a proteção do adulto têm papel de destaque para que a criança possa desenvolver-se em sua plenitude. ${ }^{3}$

Consideramos que a criança não é um adulto pequeno, e sim um ser diferenciado, que está se desenvolvendo, aprendendo e conhecendo o mundo ao seu redor, de acordo com as capacidades apreendidas em cada fase do desenvolvimento. Dessa forma, a sua forma de se expressar é diferente do que é esperado por um adulto, ou seja, a criança possui sua própria linguagem, seja ela verbal ou comportamental. Nesta fase da vida, 0 adulto/familiar responsável deve saber entender a criança, transmitindo a ela segurança, confiança e permitindo que ela se expresse e se desenvolva não somente fisicamente, mas também emocionalmente, de forma saudável e segura.

No entanto, a violência contra a criança cada vez mais está presente na vida cotidiana da população, trazendo sérias consequências para a saúde e qualidade de vida não apenas para a criança, mas para toda a coletividade. Estima-se que $10 \%$ das crianças que chegam a um serviço de emergência em saúde sofrem maus-tratos, em sua maioria intradomiciliares, ocultos e repetitivos. ${ }^{4}$

$\mathrm{Na}$ instituição onde esta pesquisa foi realizada, considerada referência no atendimento à criança vítima de violência sexual, os números apontam que, no ano de 2005 , foram atendidas 244 crianças e adolescentes vítimas de violência, sendo que algumas delas foram vítimas de mais de um tipo de violência. As agressões estiveram distribuídas em 11 por negligência, 38 por agressão, 49 por agressão física e 188 por agressão sexual. ${ }^{5}$

Existem várias formas de violência contra a criança, dentre elas: a violência intrafamiliar, que é definida como a violência, negligência ou abuso que são praticados no ambiente familiar e envolve toda ação ou omissão por parte do adulto cuidador que resulte em dano ao desenvolvimento físico, emocional, intelectual e social da criança; a violência extrafamiliar, que é a violência a que estão sujeitas todas as crianças, que pode ser praticada por conhecidos de sua convivência, por estranhos ou instituições e que nem sempre é de conhecimento dos 
responsáveis; e a autoagressão, que é entendida não apenas por atos caracterizados como tentativa de suicídio, mas também por comportamentos de risco. ${ }^{4}$

A violência sexual infantil pode acontecer no meio intrafamiliar ou extrafamiliar e compreende qualquer situação, ato ou jogo sexual, relação heterossexual ou homossexual em que a criança gratifica sexualmente 0 abusador, um adulto ou adolescente mais velho. ${ }^{6}$

Entendemos que, quando se pensa em uma criança dentro de seu próprio lar, acredita-se que esta se encontra protegida pela família. Não é normal pensar que esta esteja correndo risco de sofrer violência no próprio âmbito doméstico. 0 que nos surpreende é constatar justamente o contrário, que, em algumas situações, a criança, dentro do lar, não somente está sujeita a riscos, mas sofre vários tipos de violência, dentre eles a violência sexual.

A etiologia do abuso infantil não é bem elucidada; entretanto, acredita-se que há uma interação entre os fatores que podem predispor à prática da violência intrafamiliar. Os motivos que geralmente deflagram o processo de violência são: estresse ambiental, como o estresse, a pobreza, o desemprego, a má condição de moradia, o alcoolismo e as drogas, características de personalidade dos pais e as características da criança. ${ }^{7}$

Percebemos que, atualmente, tem-se constatado na sociedade um alto índice de pobreza, em que o desemprego e a desigualdade social, dentre outros fatores, têm desencadeado uma desestruturação familiar e altos índices de violência. Dessa forma, a violência adentra a família e atinge os seus membros, entre eles, a criança.

É triste constatar que a criança é violentada no seu próprio lar, onde por vezes sofre agressões verbais e, principalmente, agressões físicas. É difícil imaginar uma criança sendo maltratada pela própria família ou por adulto com quem ela convive. Pensamos que, dentre as formas de violência, a violência sexual é a que traz mais consequências para sua vida, pois, além de envolver o físico, afeta seu emocional de forma profunda, provocando marcas que ela vai levar para a fase adulta.

A criança violentada sexualmente pode passar por alterações bruscas de comportamento, tais como alteração no sono, queda brusca no rendimento escolar, medo inexplicável de ficar sozinho na presença de adultos estranhos ou de algum adulto específico e realizar brincadeiras agressivas com brinquedos ou pequenos animais, entre outros. A criança também pode apresentar dificuldade em sua adaptação afetiva e pode sofrer os efeitos do pacto do silêncio, sendo vítima de ameaça e pressões para não revelar o abuso.?

Os efeitos da violência sexual nas crianças em longo prazo, ou seja, que são observados na fase adulta, estão compreendidos em problemas de ajustamento sexual, problemas interpessoais e sentimento de autodesvalorização, que estão diretamente ligados ao sentimento de culpa. ${ }^{2}$
Desta forma, quanto mais precoce a violência sexual contra a criança for detectada, menos traumas e consequências ela sofrerá, tanto durante a infância quanto na fase adulta.

\section{0 cuidado de enfermagem à criança vítima de violência sexual}

A porta de entrada para o atendimento à saúde de crianças vítimas de violência sexual, pelo SUS, são as unidades de saúde para os casos leves e moderados e os hospitais de emergência para os casos graves, quando se trata de lesões que exigem atendimento hospitalar. ${ }^{4}$ Conforme o protocolo da Secretaria Municipal de Saúde, as crianças vitimizadas devem ser encaminhadas para os hospitais de referência, até 12 anos de idade. Porém, muitos casos são encaminhados diretamente pelos familiares aos hospitais de referência para o atendimento.

Quando a criança que sofre violência sexual é encaminhada ao serviço de emergência hospitalar de referência, deve, desde sua chegada, permanecer em uma unidade de internação e, após a alta, ser atendida por uma equipe multiprofissional para que todas as suas necessidades e de sua família sejam contempladas. Sabe-se que, nem sempre, o familiar/responsável que busca atendimento hospitalar para esta criança revela a veracidade da violência ocorrida.

Dessa forma, o reconhecimento dos sinais das várias formas de violência contra crianças deve, portanto, fazer parte da rotina dos profissionais da saúde, assim como a abordagem dessas situações, que, às vezes, é de extrema complexidade. Estar atento para suspeitar ou comprovar a existência de maus tratos requer, além de habilidade, sensibilidade e compromisso com esta causa.

Entre os profissionais envolvidos neste cuidado à criança, estão o enfermeiro e a equipe de enfermagem. A essência da enfermagem, o cuidado, tem como enfoque principal "o bemestar e o confor to do cliente, que exige dos profissionais um esforço constante no entendimento da complexidade e fragilidade do ser humano sob sua responsabilidade"8:59. Este ser humano, é entendido neste estudo como a criança que sofreu violência sexual e sua família/responsável que a acompanha.

0 cuidado à criança, em qualquer situação de enfermidade, diferencia-se do cuidado ao adulto por suas especificidades e particularidades, que devem ser abordadas de forma singular, em cada fase de seu crescimento e desenvolvimento. Nas situações emergenciais, como no caso da violência sexual, a criança é quase sempre a principal vítima, necessitado, dessa forma, de uma atenção especial, dadas as peculiaridades biológicas e psicológicas e as características próprias desse grupo populacional, necessitando de recursos materiais e humanos especializados para o atendimento. ${ }^{9}$

A equipe de enfermagem de um serviço de emergência deve dispor de protocolos para a assistência de enfermagem, que garantam a continuidade de um trabalho integrado com a equipe multiprofissional, atuando na orientação e no acolhimento dos familiares. ${ }^{9}$ Dessa forma, consideramos que a 
Cuidado à criança vítima de violência sexual Woiski ROS, Rocha DLB

realização e a aplicação do processo de enfermagem, como um método de trabalho do enfermeiro que trabalha em uma unidade de emergência hospitalar, garantem a continuidade do trabalho do enfermeiro e equipe de enfermagem, integrado à equipe multiprofissional, possibilitando o cuidado integral à criança vítima de violência sexual e sua família.

0 processo de enfermagem é considerado como um modelo metodológico para o cuidado profissional de enfermagem, um meio utilizado para organizar as condições necessárias à realização do cuidado e para documentar a prática profissional. Este método de trabalho deve ser fundamentado em um sistema de valores e crenças morais e no conhecimento técnico-científico da área de atuação do enfermeiro. ${ }^{10}$

0 processo de enfermagem divide-se em fases, as quais, realizadas de forma articulada, permitem a realização do cuidado de forma científica e integral. São elas: o histórico de enfermagem, que se divide em entrevista e exame físico, os quais têm por objetivo o levantamento dos dados da criança e do familiar/responsável que a acompanha; o diagnóstico de enfermagem, o qual proporciona a seleção das intervenções de enfermagem visando ao alcance dos resultados pelos quais o enfermeiro é responsável; a prescrição de enfermagem, a qual irá coordenar a ação da equipe de enfermagem na execução dos cuidados adequados ao atendimento das necessidades da criança e familiar/responsável; e a evolução de enfermagem, em que o enfermeiro avalia as respostas do paciente e analisa se as metas e os objetivos foram alcançados.

A equipe de enfermagem, em todas as fases do processo de enfermagem, deve conquistar a criança, criando um vínculo de confiança, e expressar no cuidado atitudes sinceras e verdadeiras. Também deve familiarizar a criança ao ambiente hospitalar e às pessoas que estarão envolvidas no seu cuidado, procurando explicar sobre as rotinas e os procedimentos que serão realizados, o porquê de cada um, a possibilidade de dor ou demora, sempre transmitindo confiança e afeto.?

Cabe ressaltar que os profissionais que cuidam da criança neste momento tão peculiar devem estar preparados também psicologicamente e emocionalmente. Estes profissionais que atuam em unidade de emergência devem receber, além de treinamento específico, tanto técnico quanto científico, uma educação continuada voltada para 0 autoconhecimento, o que exige deles domínio de suas próprias emoções e conhecimento de seus limites e de suas possibilidades. $^{9}$

\section{CAMINHO METODOLÓGICO}

Para a realização deste estudo, optou-se pela pesquisa qualitativa, por meio do método exploratório-descritivo.

A pesquisa qualitativa envolve a coleta e análise sistemática de materiais narrativos mais subjetivos e utiliza procedimentos nos quais a tendência é um mínimo de controle imposto pelo pesquisador. ${ }^{11} \mathrm{~A}$ investigação exploratória permite ao investigador aumentar sua experiência em torno de
Esc Anna Nery Rev Enferm 2010 jan-mar; 14 (1): 143-50

determinado problema, podendo ser descrita quando observa, registra, analisa e correlaciona fatos com os fenômenos sem manipulá-los. As pesquisas descritivas têm como objetivo primordial a descrição das características de determinada população ou fenômeno. ${ }^{12}$

0 método exploratório-descritivo foi apropriado para este estudo, pois permitiu a exploração do problema, tornando-o familiar para a pesquisadora, a primeira autora deste artigo, permitindo conhecer as suas relações com os seres humanos envolvidos neste contexto, ou seja, a criança, o familiar/ responsável que a acompanha e a equipe de enfermagem.

0 local onde o estudo foi realizado foi o setor de emergência de um hospital infantil de grande porte, referência na cidade de Curitiba, com especialidades exclusivas no atendimento de crianças e adolescentes e serviços de alta complexidade. A entrada no campo se deu pela necessidade da realização do estágio supervisionado em unidade hospitalar, das disciplinas de estágio supervisionado I e II. Dessa forma, optou-se por escolher o local do estágio supervisionado para a realização da pesquisa.

Os sujeitos do estudo foram 11 profissionais da equipe de enfermagem que trabalham no setor de emergência nos turnos da manhã, tarde e noite, seguindo os critérios de inclusão: ter cuidado de criança vítima de violência sexual e aceitar participar do estudo.

A idade dos sujeitos variou de 26 a 53 anos. Quanto à formação profissional, quatro eram enfermeiros; seis, técnicos de enfermagem; e um, auxiliar de enfermagem; o tempo de serviço no setor de emergência variou de 3 a 19 anos. 0 número previsto de sujeitos não foi determinado antes do início da coleta das informações, pois dependeu dos depoimentos apreendidos pelos entrevistados, à medida que as informações foram sendo saturadas, ou seja, quando se iniciou a repetição das falas.

Para a coleta das informações utilizou-se a entrevista semiestruturada, a qual combina questões abertas e fechadas, facultando ao entrevistado discorrer sobre 0 assunto em foco. ${ }^{13}$ A opção pela entrevista semiestruturada se deu pela flexibilidade que o modelo permite ao combinar questões fechadas e abertas no transcorrer do discurso, o que favoreceu a liberdade de expressão.

A questão de pesquisa, a partir da questão norteadora foi: como você percebe o cuidado de enfermagem à criança vítima de violência sexual atendida em unidade de emergência hospitalar? Após a realização desta pergunta aos sujeitos, seguiram-se as perguntas complementares, elaboradas com vistas a responder aos objetivos da pesquisa.

Para apreender o significado dos discursos dos sujeitos, foi utilizada a Análise de Conteúdo de Bardin. Esta análise permite, pela sua técnica, ir além das aparências e descobrir o real significado dos discursos sem negligenciar o rigor científico. ${ }^{14}$

Para a análise de conteúdo, seguimos os passos da préanálise: nesta fase, o material coletado foi transcrito e foi 
realizada uma leitura flutuante; exploração do material: 0 material coletado foi organizado em unidades de contexto e significação; e tratamento dos resultados obtidos e interpretação: os resultados brutos foram tratados de maneira a tornarem-se significativos. ${ }^{14}$

As entrevistas foram realizadas e gravadas no mês de julho de 2008, e os encontros foram pré-agendados em local que permitiu a privacidade dos sujeitos e possibilitou a livre expressão de ideias. No desenvolvimento deste estudo foram respeitados o Código de Ética Profissional e a Resolução 196/96 que levam em conta princípios éticos básicos que devem orientar os estudos envolvendo seres humanos, a saber, o respeito pela pessoa, a beneficência, a justiça, a fidelidade, a veracidade e a confidencialidade. ${ }^{15}$

Conformando essas questões, foram escolhidos codinomes para cada sujeito que substituíram seus nomes verdadeiros, preservando assim, sua identidade. Os codinomes escolhidos foram: Lírio do Campo, Rosa Cheirosa, Dália Vermelha, Cravo Branco, Violeta Branca, Orquídea Salmão, Amor Perfeito, Flor de Maracujá, Tulipa Vermelha, Beija-flor e Moranguinho Doce.

Em atendimento à legislação vigente, este projeto foi enviado ao Comitê de Ética da instituição hospitalar desse estudo, e, somente após a sua aprovação sob o número 057608 e a assinatura do termo de consentimento livre e esclarecido pelos sujeitos, o estudo teve início.

\section{RESULTADOS}

Após minuciosa análise do conteúdo das expressões dos sujeitos chegou-se a três Unidades de Contexto e seis Unidades de Significação, que revelaram as intensas percepções da equipe de enfermagem sobre o cuidado à criança vítima de violência sexual infantil, que serão descritas a seguir.

A Unidade de Contexto - percepção da equipe de enfermagem sobre cuidado à criança vítima de violência sexual e sua família e a Unidade de Significação - impacto da chegada da criança na unidade de emergência demonstram a percepção da equipe de enfermagem no seu primeiro contato com a criança, quando percebe a criança assustada, coagida, insegura, duvidando de todos que a cercam. Nesse momento, a equipe procura demonstrar amor e carinho para que ela se sinta menos assustada.

Nos casos de violência sexual da criança, qualquer intervenção do enfermeiro deve ter como objetivo principal evitar danos maiores pela intervenção antes de se dedicar à tarefa primária de cuidar e auxiliar no tratamento do trauma decorrente da própria violência sexual. ${ }^{16}$ Daí a importância de o enfermeiro e a equipe de enfermagem transmitirem confiança e segurança para a criança.

Percebo que, no entender desta criança, é de dúvidas em relação a todos que a cercam, então procuro atender com calma, demonstrando amor e carinho porque neste momento é o que ela mais precisa, de afeto e aconchego quando possível (Lírio do Campo, Técnica de Enfermagem).

A Unidade de Significação - omissão da família e necessidade de proteção do causador da violência sexual contra a criança, percebida pela equipe de enfermagem, revela que, quando a violência é causada por um familiar, na maioria das vezes a própria família protege o causador da violência, em vez de proteger a criança, o que também causa muita revolta na equipe. 0 papel do pai, assim como o da mãe, em um dos padrões normais de uma família, envolve comprometimento emocional e, com frequência, envolvimento direto no cuidado e na educação dos filhos. ${ }^{17}$

\begin{abstract}
Não consigo entender, me refiro também à omissão das mães defendendo os "cavalões" que praticam tal ato, que na maioria das vezes é o próprio pai ou a mãe, tio, primo e até mesmo avós [...] porque quem deveria estar sendo protegida é a criança, não estes"trogloditas malfeitores"(Lírio do Campo, Técnica de Enfermagem).
\end{abstract}

A Unidade de Contexto - sentimentos despertados na equipe ao cuidar da criança vítima de violência sexual e a Unidade de Significação - sentimentos vivenciados pela equipe de enfermagem ao cuidar da criança vítima de violência sexual demonstram os sentimentos de pena, dor e sofrimento, relatados como sentimentos incontroláveis relacionados à criança, e revolta e raiva, relacionadas à pessoa que cometeu a violência sexual contra a criança.

É bem difícil, porque a gente fica com muita peninha da criança e muito indignada com o abusador, na verdade é um desafio pra gente (Beija-flor, Enfermeira).

A Unidade de Significação - desejo de justiça relatado pela equipe de enfermagem ao cuidar da criança vítima de violência sexual demonstra o desejo que a equipe tem em realizar a justiça pelas próprias mãos, pois querem que 0 abusador sofra da mesma forma que fez a criança sofrer.

0 profissional percebe, ao atender uma criança vítima de violência sexual, que sua inocência é interrompida pelo ato silencioso da violência, e que haverão marcas profundas em sua vida, deixando o pensamento comprometido em relação ao adulto agressor, ainda mais sabendo que os pais e padrastos são os maiores culpados nestes acontecimentos e ainda dentro dos próprios lares. ${ }^{18}$ Ao perceber esta realidade, a equipe se revolta, não consegue entender, sofre devido ao grande sofrimento da criança. 
Cuidado à criança vítima de violência sexual Woiski ROS, Rocha DLB

Quando a gente fica sabendo que é da própria família, eu tenho vontade de fazer justiça com as minhas mãos, é uma revolta tão grande que você não tem noção, da vontade de fazer picadinho do responsável pelo caso, é um sentimento incontrolável no momento (Tulipa Vermelha, Técnica em Enfermagem).

A Unidade de Significação - a fé como suporte e agente transformador da tristeza em esperança demonstra que a equipe de enfermagem coloca sua fé e esperança em Deus para que o mundo seja melhor, para que a violência contra a criança não volte a acontecer, para que o abusador se arrependa e para que a própria equipe tenha forças para realizar o cuidado diante dessa situação de sofrimento da criança.

Gostaria que houvesse mais respeito entre seres humanos, acho que é falta de Deus nas familias, as pessoas estão esquecendo-se de rezar, de buscar a proteção divina para suas famílias (Lírio do Campo, Técnica de Enfermagem).

Só Deus mesmo pra por bons pensamentos e limites na cabeça destas criaturas horríveis (Flor de Maracujá, Técnica de Enfermagem).

A Unidade de Contexto - características que compõem o cuidado de enfermagem à criança vítima de violência sexual em unidade de emergência hospitalar e a Unidade de Significação - cuidado de enfermagem à criança vítima de violência sexual demonstram o atendimento que é realizado à criança vítima de violência sexual na unidade de emergência, desde sua admissão, atendimento médico, cuidado de enfermagem e encaminhamento para uma unidade de internação.

Logo após a criança ser admitida, ela é atendida pelo médico de plantão, depois pelo perito do Instituto Médico Legal (IML) e somente depois disso é "liberada" para que a equipe de enfermagem realize os primeiros cuidados. 0 conselho tutelar também é acionado, pois é uma questão que envolve não somente a família, mas também a rede social da criança.

Quando chega criança vítima de violência sexual no nosso setor, é atendida diretamente pelos médicos que se encontram no momento (Flor de Maracujá, Técnica de Enfermagem).

Depois de ter passado pelo médico e autoridade sanitária, caso a criança precise de cuidados, aí vem para enfermagem (Beija-flor, Enfermeira).

A equipe de enfermagem demonstra compreender a importância de realizar o cuidado humanizado, que não se limita a ações técnicas, e sim envolve o emocional não só da
Esc Anna Nery Rev Enferm 2010 jan-mar; 14 (1): 143-50

criança, mas da própria equipe envolvida no cuidado. A equipe reconhece a importância de estar preparada psicologicamente neste momento, pois percebe que também se envolve emocionalmente. 0 enfermeiro tem atuação importante na orientação e apoio da equipe de enfermagem, ajudando-a a enfrentar as dificuldades emocionais apresentadas no momento do cuidado, além de direcionar o preparo técnico da equipe para este momento delicado e doloroso para a criança.

Na verdade é um trabalho humanizado realmente, estando todos cientes que esta criança precisa do nosso total apoio, procurando passar a verdadeira segurança para ela, pois este tipo de problema afeta mais o lado emocional; o psicológico desta criança fica muito abalado, por isso procuramos sempre estar por perto para dar um pouco de apoio e segurança (Orquídea Salmão, Enfermeira).

[...] deve de ter um cuidado especial, porque temos que estar preparadas tecnicamente nesses casos, mas muito mais emocionalmente, porque, se não, a cabeça e o coração não aguentam (Tulipa Vermelha, Técnica em Enfermagem).

A equipe de enfermagem refere que sente a necessidade de receber treinamentos específicos para este atendimento, para saber como agir nestas situações e poder realizar um cuidado individualizado à criança. Os próprios enfermeiros afirmam que não estão preparados para este atendimento e que a equipe realiza os cuidados de forma aleatória, conforme percebem na necessidade do momento. Não apontam o processo de enfermagem como método de trabalho do enfermeiro e um direcionador do cuidado que é realizado pela equipe de enfermagem.

Eu acho que aqui as enfermeiras não estão preparadas para o atendimento destes casos e nem mesmo percebo um interesse por parte delas (Beija-flor, Enfermeira).

Eu acho que deveria ter treinamentos para os setores que atendem estes casos, pois atendemos aleatoriamente as crianças (Violeta Branca, Técnica de Enfermagem).

Sobre método de atendimento de criança vítima de abuso sexual, eu nunca vi por aqui, atendemos aleatoriamente, sempre conforme a necessidade de cada caso (Orquídea Salmão, Enfermeira).

\section{DISCUSSÃO}

Ao concluir a análise dos dados, percebemos que a equipe de enfermagem, apesar do primeiro impacto ao receber a criança 
vítima de violência sexual na unidade de emergência, tenta controlar suas emoções e sentimentos para poder transmitir segurança e confiança para a criança. Ao observar 0 comportamento dos familiares que acompanham a criança, questiona o fato de estes omitirem a ação de violência praticada contra a criança e até protegerem o abusador. Este fato gera muita revolta na equipe de enfermagem, pois não consegue entender como aqueles que por natureza deveriam proteger a criança podem realizar um ato de violência contra ela.

0 enfermeiro e a equipe de enfermagem têm um importante papel neste momento, pois podem, por meio do cuidado, apoiar a criança, transmitir 0 amor e a segurança de que ela precisa para enfrentar essa situação. Pelas falas, percebe-se que esse envolvimento da equipe com a criança e familiar é desgastante, gera muitos conflitos e questionamentos. Dessa forma, salientase a importância de um preparo emocional da equipe de enfermagem diante deste contexto de cuidado.

Fica evidente também que, apesar desta gama de emoções e sentimentos, a enfermagem busca o conforto, a proteção, 0 zelo pela criança, superando sentimentos negativos e visando o seu bem-estar. A fé foi relatada como fonte de força, refúgio e alento, pois a equipe de enfermagem acredita que Deus, um ser superior, pode mudar esta situação, trazer justiça, dar forças para a criança e para a equipe que cuida e até trazer arrependimento ao malfeitor.

Quando chega à unidade de emergência, a criança é atendida pelo médico de plantão, o qual aciona o perito do IML e o conselho tutelar. Neste momento, não se percebe a atuação da enfermagem, a qual participa do atendimento somente caso o médico precise de auxílio. Logo após a criança ser avaliada pelo médico e perito, o médico do setor prescreve os primeiros cuidados e as medicações a serem administradas na criança. A equipe de enfermagem executa a prescrição médica e, conforme relatado nas falas, na maioria das vezes, a enfermeira do setor não entra em contato com a criança.

A equipe refere cuidar sem um método específico, ou seja, sem seguir o processo de enfermagem, o qual é de responsabilidade legal do enfermeiro, a fim de direcionar as ações de cuidado da equipe de enfermagem. A equipe relata a necessidade que sente de receber treinamentos específicos para este tipo de atendimento, tanto tecnicamente como psicologicamente, já que este cuidado toca no emocional de todos.

\section{CONSIDERAÇÕES FINAIS}

Conhecer como a equipe de enfermagem percebe o cuidado efetivado à criança que sofreu violência sexual ao ser atendida em unidade de emergência hospitalar foi um desafio, o qual foi superado e permitiu ampliar o olhar e refletir sobre o cuidado de enfermagem neste contexto de cuidado tão específico.

Ao concluir este estudo, nota-se que a percepção da equipe de enfermagem sobre o cuidado à criança vítima de violência sexual vai muito além da execução de uma técnica, ou cuidado com as alterações físicas, pois ela se envolve com a criança e família de tal forma que dessa relação emerge uma gama de sentimentos e emoções que influenciam diretamente na realização do cuidado.

A equipe de enfermagem sente comoção diante deste contexto de cuidado ao perceber que este sofrimento da criança não foi simplesmente causado por uma doença ou trauma frutos de um acidente, aos quais toda a população está sujeita. Pelo contrário, o sofrimento da criança advém de uma violência, de um abuso, que na maioria das vezes é causado por um adulto agressor, contra uma criança indefesa.

Dentre as características que compõem o cuidado de enfermagem, além do cuidado humanizado percebido nas falas dos sujeitos, percebe-se a falta da sistematização da assistência deste cuidado, pelo processo de enfermagem. Ficou evidente a ausência do enfermeiro como direcionador do cuidado realizado pela equipe, sendo que, muitas vezes, a equipe percebe 0 enfermeiro distante neste momento.

Considera-se que o enfermeiro e a equipe de enfermagem têm papel fundamental no atendimento a esta criança em unidade de emergência hospitalar, não somente como suporte ou forma de auxílio para o médico, ou meros executores de prescrições, mas sim como profissionais que têm atribuições e responsabilidades profissionais próprias, em que o cuidado é o foco principal de atenção e o processo de enfermagem, o método de trabalho.

Os profissionais da enfermagem precisam ter consciência de suas atribuições, suas competências legais no que tange à Lei do Exercício Profissional, que rege a profissão da Enfermagem e, além de conhecer e se conscientizar, devem assumir as suas responsabilidades diante destes preceitos legais. 0 cuidado de enfermagem deve ser prescrito por enfermeiro e realizado por toda a equipe de enfermagem, e entende-se que, é por meio da aplicação do processo de enfermagem que ambos, juntos, caminham em direção ao seu objetivo maior, a realização do cuidado de enfermagem com qualidade, de forma individual a cada paciente, que atenda às suas reais expectativas e necessidades.

Compreende-se que, tendo as suas atribuições profissionais bem definidas e conhecidas e aplicando a metodologia da assistência, direcionando o cuidado, enfermeiro e equipe de enfermagem ocupam o seu papel dentro da equipe multiprofissional no atendimento à criança, tornando-se responsáveis e executores da parte que lhes cabe, que é o cuidado. Dessa forma, a enfermagem terá sua valorização profissional diante da equipe multiprofissional, paciente e família.

Além disso, dentre as atribuições do enfermeiro, está a de educador, e considera-se de extrema necessidade que este capacite sua equipe para a realização do cuidado dentro do contexto de trabalho em que estão inseridos, e a realização de treinamentos, dinâmicas de grupo, entre outros programas, pode instrumentalizar, fortalecer e encorajar a equipe para 
este atendimento e, assim, trazer benefícios para o paciente, neste caso a criança vítima de violência sexual.

Os resultados encontrados com a análise contribuem para novas reflexões sobre esta temática, tendo em vista 0

\section{REFERÊNCIAS}

1.Deslandes SF. Prevenir a violência: um desafio para os profissionais de saúde. Rio de Janeiro (RJ): FIOCRUZ /Claves; 1997.

2.Azevedo MA, et al. Infância e violência intrafamiliar: fronteiras do conhecimento. São Paulo (SP): Cortez; 1993.

3.Dupas G, Oliveira I, Costa TNA. A importância do interacionismo simbólico na pratica de enfermagem. Rev Esc Enferm USP 1997 ago; 31(2): 219-26.

4.Prefeitura Municipal de Curitiba. Rede de proteção à criança e ao adolescente em situação de risco para a violência. Manual de atendimento, 1. Curitiba (PR); 2002.

5.Hospital Pequeno Príncipe. Violência contra a criança. 2008. [online] [citado 20 ago 2008]. Disponível em: http:// www.pequenoprincipe.org.br.

6.Ministério da Saúde (BR). Notificação de maus-tratos contra as crianças e adolescentes pelos profissionais de saúde: um passo a mais na cidadania em saúde. Brasília (DF); 2002.

7.Vitiello N. Violência sexual contra crianças e adolescentes. Femina, Febrasgo 1989 dez; 17(12).

8.Silva MBGM, Tonelli ALN, Lacerda MR. Instrumentos do cuidado humanizado de enfermagem: uma reflexão teórica. Cogitare Enferm 2003 jan/jun; 8(1): 59-64. aprimoramento do cuidado e o despertar para novas práticas de cuidado do enfermeiro à criança vítima de violência sexual. Por meio do pensamento e da reflexão, o enfermeiro pode alcançar as transformações tão desejadas em sua prática profissional, com vistas a torná-la mais visível e qualificada.

9.Tacsi YRC, Vendruscolo DMS. A assistência de enfermagem no serviço de emergência pediátrica. Rev. Latino-am Enfermagem 2004 maio/ jun [citado 20 ago 2008; 12(3): 477-84. Disponível em: www.scielo.br/

10. Garcia TR, Nóbrega MML. Processo de enfermagem: da teoria à prática assistencial e de pesquisa. Esc Anna Nery Rev Enferm 2009 mar; 13(1): 188-93.

11.Polit DF, Hungler BP. Fundamentos de pesquisa em enfermagem: métodos, avaliação e utilização. $5^{a}$ ed. Porto Alegre (RS): Artmed; 2004.

12.Gil AC. Como elaborar projetos de pesquisa. $4^{\mathrm{a} e d}$. São Paulo(SP): Atlas; 2002.

13.Minayo MCS. Interdisciplinaridade: uma questão que atravessa o saber, o poder e o mundo vivido. São Paulo (SP): Abrasco; 1986.

14.Bardin L. Análise de conteúdo. Rio de Janeiro (SP): Ed 70. p.191.

15.Ministério da Saúde (BR). Conselho Nacional da Saúde. Resolução n. ${ }^{0}$ 196/96. Sobre pesquisa envolvendo seres humanos. Diário Oficial da República Federativa do Brasil, Brasília, 10 out. 1996.

16.Furniss T. Abuso sexual da criança: uma abordagem multidisciplinar. Porto Alegre (RS): Artes Médicas; 1993.

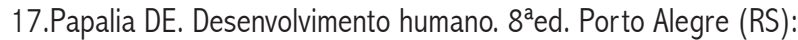
Artmed; 2006.

18.Minatel VF, Simões RO. A trilha para demonstrar uma prática baseada em evidências-guias de conduta de enfermagem. In: Bork AMT, organizadora. Enfermagem de excelência: da visão a ação. Rio de Janeiro (RJ): Guanabara Koogan; 2003. 